\title{
Construction and abstraction: contrasting methods of supporting model building in learning science
}

\author{
ROSEMARY LUCKIN AND B ENEDICT DU B OULAY \\ School of Cognitive \& Computing Sciences, \\ University of Sussex, \\ Brighton, BN1 9QH, UK. \\ email: rosel@cogs.susx.ac.uk and bend@cogs.susx.ac.uk.
}

\section{Introduction}

Interactive Learning Systems can offer students a range of representations, tools, environments and assistance to construct a model which reflects their understanding of a situation which exists in the real world. They can also offer a range of possibilities for learners to improve their communicative competence and articulate their understandings to themselves, to others or to the system itself. However, the relationship between interactivity, learning and communication is complex and can involve humans, artefacts or a combination of both. Theories based on the promotion of productive interactivity between humans in order to engender individual learning development, such as that of Vygotsky (Vygotsky, 1978; Vygotsky, 1986) can be found at the heart of much work on the design of Interactive Learning Environments (ILEs) (Guzdial et al., 1996; Jackson, Stratford, Krajcik, \& Soloway, 1996; Luckin \& du Boulay, 1999; Rosson \& Carroll, 1996; Wood \& Wood, 1996, for example). But what do we mean by Interactive and what is the relationship between Interactivity and Communication? Clarifying these concepts should help us build systems better able to support learners in their search for understanding. A definition of Interactivity that we have found useful is as follows:

Interactivity is the cycle of operational or conceptual exchange between two or more parties, one of which may be a digital system. Operational exchange refers to functional activity: the entering of information through a keyboard and the resultant response from the system, entering a number on the screen for example. Essentially operational interchange is at the level of individual key presses or mouse movements together with their corresponding character level or cursor movements on the screen, in the case of a computer, and individual words, spoken and heard, in the case of people. Conceptual exchange refers to activity involving the concepts of the particular topic being studied. This might involve the solution of a screen based problem activity by a user, or discussion about where chemical elements belong in 
the periodic table involving a teacher and learners completing a computer based task.

Interactivity can be considered in terms of range: it may involve interactivity with and between individuals, small or large groups, groups that are local or distributed. It can also be considered in terms of its locus: interactivity can occur both at and through the interface between interlocutors. The system's interface in the systems we describe in this chapter is a computer screen. Interactivity at the interface is deemed operational and as such it should be straightforward and intuitive. Interactivity through the interface requires interactions between users and the subject matter concepts that make up the discipline of study. This distinction is similar to that made by Laurillard (1993).

In this chapter we discuss two very different approaches to the design of ILEs for science education in the classroom. The first system, Ecolab, is designed for use by an individual learner aged 10 - 11 years. It allows her to construct different miniecosystems through the availability of modelling tools and to examine different views of the model being built. The system itself also attempts to help the learner construct viable and runnable models that accurately reflect the relationships between organisms in the real world. The second example, Galapagos, is drawn from a system designed for use by groups of older learners, aged 15 - 21, who need to collaboratively write a description of the process which has lead to the evolution of different variations of the same species of organism. Although the material that learners can draw upon to write an answer is varied, rich and multi-media, the representation that they can use to formulate their model of the process is static: a textual notepad.

The two systems supported contrasting kinds of modelling and communicative activity. In the first the models were runnable and could be constructed from a predefined kit of objects and actions. These could be assembled into mini-ecosystems and observed running. The modelling activity was essentially a "bottom-up" process of building an understanding of a complex system by first understanding its parts and then understanding how those parts interact in models of increasing complexity. Learning support for this endeavour was provided by the tools for guiding the development of the sequence of runnable models and for observing them from different viewpoints. In this instance, communication was between computer and a single learner, though the system could have been used by groups (but was not). In the second system the theory of evolution was presented through text, diagrams, pictures and video clips. The modelling activity of the students was to build a non-runnable descriptive model. This meant that they had to abstract away from the rich detail of the learning materials to "reveal" the bare bones of the underlying evolutionary processes. Learning support for 
this activity was provided by the interactions with the other students as they struggled to articulate to each other and themselves the nature of the theory. Here the partial and imperfect descriptions of the other students' functioned in a similar way to the tools for observing models from different perspectives provided in the first system. Interaction and communication was between individual members of the group and each other, individuals and the system and the group and the system. We use case studies of both systems to tease out some of the factors that have proved successful in linking support for learning as communicative competence, and for the process of modelling.

Our view of learning science is that both kinds of modelling are important. The young scientist needs to work with 'formal' tools such as mathematics or simulations, as in Ecolab, that focus attention on central concepts, crucial variables and important relationships. In other words, the detail and 'messiness' of the real world needs to be stripped away to reveal essential structures and an underlying simplicity. But to really understand this simplicity, learners also need to take part in the activity of "stripping away complexity", typically through discussion. It is through discussion that they can come to understand how the simplified model stands in relation to the more complex reality and embed the understanding of these phenomena in the wider context of their other knowledge.

This paper is in three parts. The next section describes the Ecolab adaptive system able to adjust itself to an individual learner and designed to support one-to-one interaction. This interaction was largely concerned with modelling within a simulation. This section describes how three different variants of the system produced different kinds of modelling behaviour in their users. The following section describes the adaptable system Galapagos, again implemented as three variants, and again producing rather different modelling behaviours. This system was designed to support groups of learners and to provoke focused discussion. The final section compares the two methodologies. 


\section{Case Study 1: The Ecolab: modelling an ecosystem}

\section{The Ecolab Software}

The first case study involves the Ecolab software that provides 10 -11 year old children with the facilities to model feeding relationships in a simulated ecology laboratory environment. Ecology is a subject that involves the study of relationships between organisms within an environment. These relationships can be extremely complex, but they can also be introduced in a simplified manner through concepts such as food chains and food webs. These form the foundations of more complex ecosystems and are part of the curriculum for primary school children in the United Kingdom. In the Ecolab children can select animals and plants and then build, activate and observe the relationships that exist between members of a simple food web in a woodland ecosystem. This environment can be viewed from several different perspectives, including:

1. World - a picture of a woodland environment and the organisms the child has chosen to place within it.

2. Web - a traditional textbook style diagram of the organisms in a food chain and food web.

3. Energy - a graphical representation of the energy levels of the organisms currently 'alive' in the Ecolab: See Figure 1.

4. History - a Linear narrative of what has happened in the Ecolab world to date, which animal has eaten which other animal for example. 


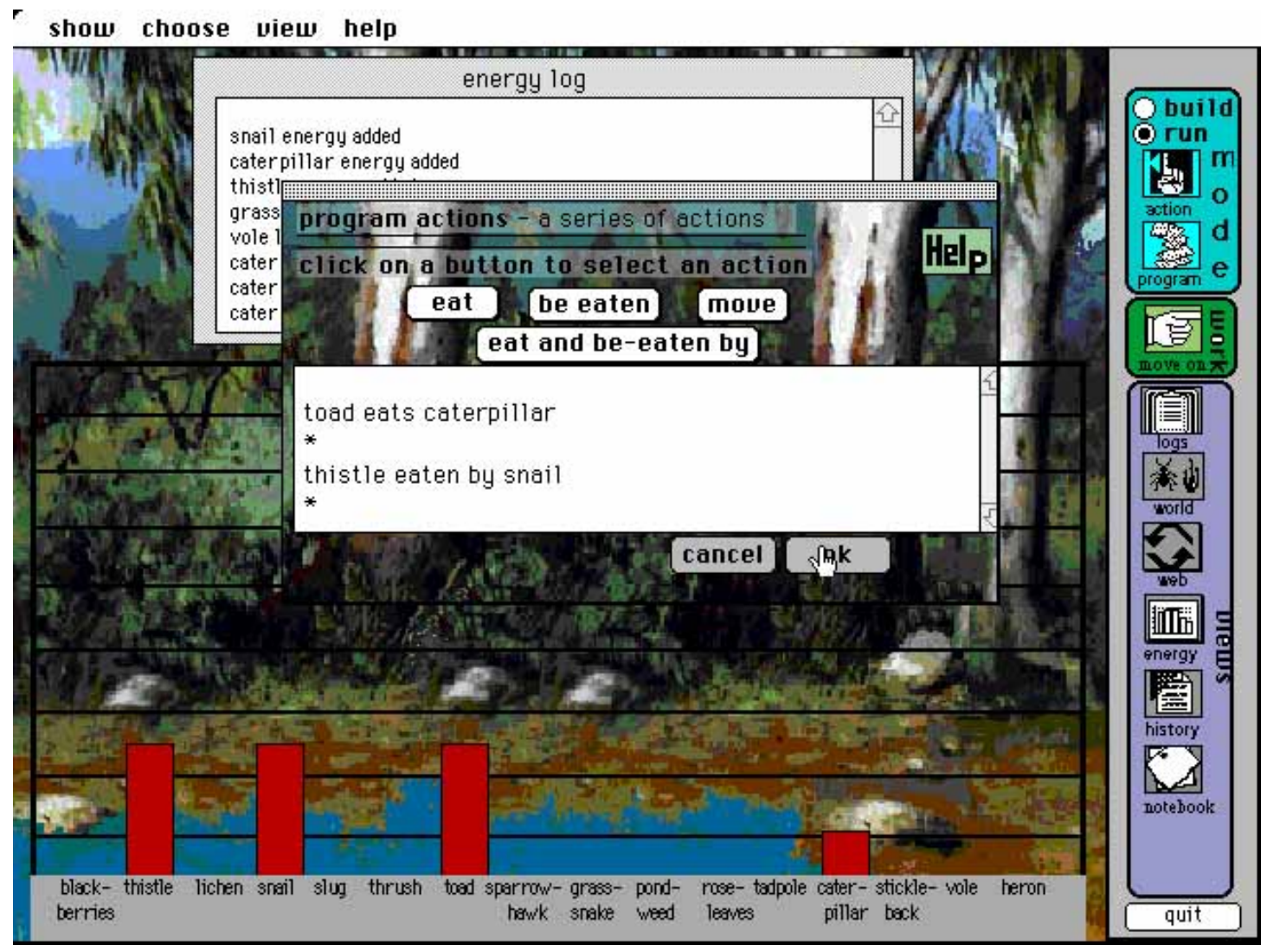

Figure 1. Ecolab Energy view

As we have already stated, the nature of the relationships which can exist between organisms in the real world can be very complex. The software was designed to allow each of the children using it to learn about relationships at a level of complexity that was appropriate to them. It was built in a manner that allows children to learn about relationships ranging from the simplest, between just two single organisms, up to the more complex network of relationships that could exist even in a very simple ecosystem with populations of organisms. The complexity of the relationships represented within the Ecolab can be varied at any stage during the child's interaction with it. It is also possible to alter the abstractness of the terminology used to describe the organisms in the Ecolab so that a snail, for example, can be described by the words "herbivore", "primary consumer", or "consumer" as well as by the word "snail".

In addition to this simulated laboratory environment, the system offers each learner a collaborative learning partner that can provide assistance of the following sorts:

1. Extension of the learner's knowledge through increasing the complexity of the relationships that she is asked to study and/or the abstractness of the terminology used to describe what is happening in the Ecolab. 
2. Collaborative Support which can take the shape of

- Activity Differentiation: in the form of alterations to the difficulty of the activities the learner is asked to complete, or

- context sensitive Help of variable levels of quality and quantity.

The theoretical foundations underpinning the design of the Ecolab can be found in the Zone of Proximal Development (Vygotsky, 1978; Vygotsky, 1986). Great emphasis is placed upon the importance of collaboration between more able and less able members of an interactive learning partnership. The partnership in the Ecolab is between the system and an individual learner: the system acting as the more able partner with a responsibility for giving the learner opportunities to tackle challenging activities as well as support to ensure their successful completion. The Ecolab therefore provided its child users with modelling tools and opportunities to enter into a collaborative partnership. Communication between partners, i.e. the system and the child, is through the interface in the shape of the commands invoked by the child and the visual feedback provided by the system. The following scenario illustrates the type of interactions that could occur:

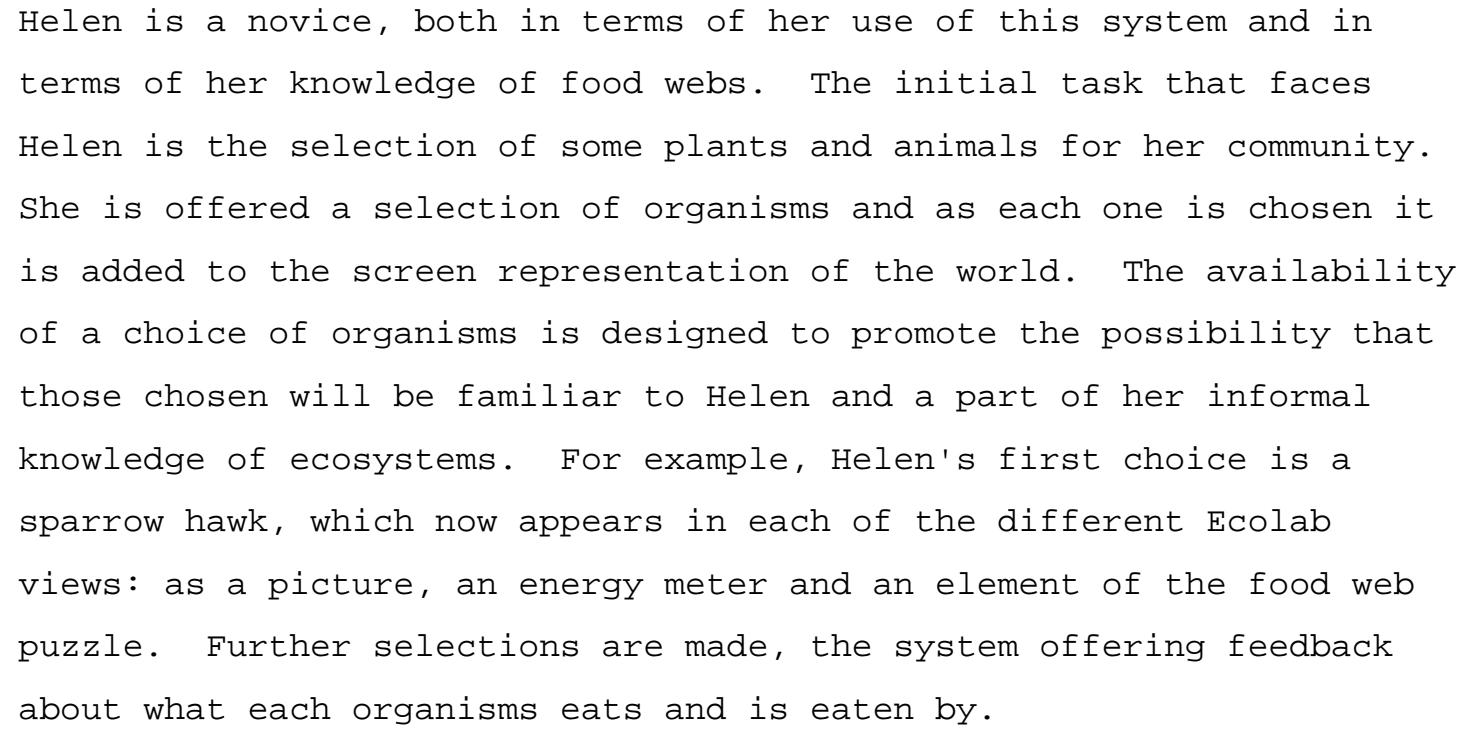

- What happens to the energy level of the sparrow hawk when it eats the thrush? 
- Why does the thrush eat the snail?

- How does the snail get enough energy to live?

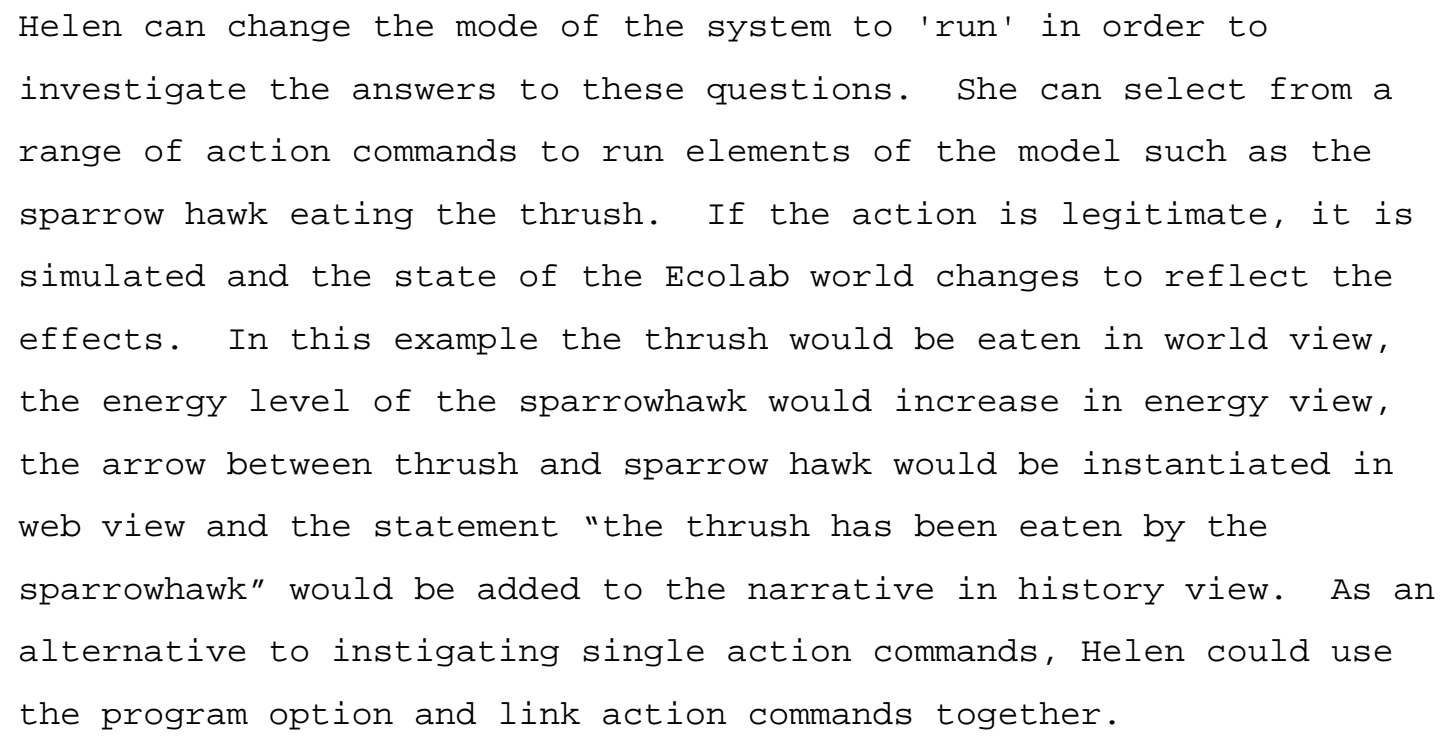

The above brief description illustrates how Helen can interact with the Ecolab and it explains the types of activities that she encounters. However what is not clear from this text is how the system acts as a more able collaborative learning partner. This will now be clarified. As has already been identified there are two basic types of assistance available. First, there are help statements that can be of 5 different levels of specificity. For example, if Helen has difficulty in answering the investigation questions, the system can prompt generally with "try setting the world to 'run' and see what happens" or, more specifically, with "try using the action commands to make the sparrow hawk eat the thrush and look in the energy view to see the changes". The most specific help, i.e. that in which the system takes the greatest control, would be a demonstration of selecting the action command to make the sparrow hawk eat the thrush and then switching to energy view to see the outcome.

The second category of assistance consists of the manner in which the activity presented to Helen can be adjusted. The adjustments possible in the current implementation are organised into two levels. The first level incorporates two types of adjustment. First, the number of organisms used in the activity is restricted to those that exhibit the relationship or features which is currently the subject of instruction. Second, when the child is required to select an answer, or construct an answer from its constituents, the number of possible wrong answers or constituents is reduced. The second level of adjustment also encompasses two kinds of alteration in addition to those utilised for level one. First, some of the elements of the activity are already completed and, 
second, any rule refinements are ignored. In the current example this would mean that Helen would be introduced to the rule that energy is transferred from food to feeder, but not that some of the energy is dispersed.

Once Helen has completed this activity, a new activity of appropriate complexity will be needed. If she has found the current task straightforward then a more challenging activity will be needed, alternatively if this one has proved tough, then an easier option is needed. It might also be appropriate to alter the nature of the terminology used to describe the plants and animals Helen has selected. A move to more abstract terminology will mean that in the next and future activities Helen will be required to manipulate concepts such as carnivore rather than sparrowhawk. She will need to understand the relationships that exist between the organisms in terms of their roles rather than in terms of their category instances. Such roles are likely to be less familiar to Helen and therefore more difficult. If however such a move presents Helen with an unreasonable degree of difficulty then the level of abstraction can be lowered again.

Although we have stipulated that the interactions that occur in the Ecolab are between a system and a single learner, we have not specified which of these partners is responsible for making decisions about what the learner should do next, how difficult it should be and how much help the system should give. In fact the Ecolab is not a single system: there are three system versions in which this responsibility and the manner in which collaboration from the system was offered to the learner is varied. The three system variations are: VIS (Vygotskian Inspired System), WIS (Woodsian Inspired System) and NIS (Non-theoretically Inspired System). The way in which each of the system variations adopts a different approach is described in more detail in Luckin (1998) and is summarised in Table 1. 
Table 1. Collaborative Support within Ecolab

\begin{tabular}{|c|c|c|c|}
\hline \multicolumn{4}{|c|}{ Collaborative Support within Ecolab } \\
\hline & VIS & WIS & NIS \\
\hline $\begin{array}{l}\text { Levels of Help } \\
\text { Available } \\
\text { (different levels } \\
\text { provide differing } \\
\text { qualities of help - } 5 \\
\text { represents the greatest } \\
\text { and } 1 \text { the least) }\end{array}$ & 5 & 5 & 2 \\
\hline $\begin{array}{l}\text { Decision about Level } \\
\text { of Help made by }\end{array}$ & system & system and child & child \\
\hline $\begin{array}{l}\text { Levels of Activity } \\
\text { Differentiation } \\
\text { Available }\end{array}$ & 3 & 3 & 3 \\
\hline $\begin{array}{l}\text { Decision about type } \\
\text { of Activity and } \\
\text { Differentiation level } \\
\text { made by }\end{array}$ & system & $\begin{array}{l}\text { child - system makes } \\
\text { suggestions }\end{array}$ & child \\
\hline $\begin{array}{l}\text { Extent of Learner } \\
\text { Model maintained by } \\
\text { the system and used } \\
\text { to make decisions } \\
\text { about the support to } \\
\text { be offered to the } \\
\text { learner. }\end{array}$ & $\begin{array}{l}\text { Bayesian Belief } \\
\text { Network (BBN) of } \\
\text { values representing } \\
\text { the system's beliefs } \\
\text { about child's ZPD } \\
\text { formed from its } \\
\text { knowledge about the } \\
\text { amount of } \\
\text { collaborative support } \\
\text { used to date. }\end{array}$ & $\begin{array}{l}\text { Record of help used } \\
\text { to enable contingent } \\
\text { calculation of next } \\
\text { help level. Record of } \\
\text { curriculum nodes } \\
\text { visited maintained to } \\
\text { permit suggestions. }\end{array}$ & $\begin{array}{l}\text { Record of Curriculum } \\
\text { nodes visited } \\
\text { maintained to help } \\
\text { child keep track. }\end{array}$ \\
\hline $\begin{array}{l}\text { Abstractness of } \\
\text { Terminology selected } \\
\text { by }\end{array}$ & system & child & child \\
\hline $\begin{array}{l}\text { Area of the } \\
\text { Curriculum and } \\
\text { complexity of the next } \\
\text { activity selected by }\end{array}$ & system & $\begin{array}{l}\text { child - system makes } \\
\text { suggestions }\end{array}$ & child \\
\hline
\end{tabular}




\begin{tabular}{|l|l|l|l|}
\hline $\begin{array}{l}\text { Ecolab View } \\
\text { selected by }\end{array}$ & mostly child & child & child \\
\hline
\end{tabular}

\section{Empirical evaluation: Modelling and collaborating with the Ecolab}

An exploratory evaluation study of the Ecolab software was conducted with a class of children aged 10 and 11 years. More detail about the methodology and results can be found in Luckin (1998). Here we focus on the types of interactions children had with the system, the nature of the models they constructed and the collaborative communication that occurred between system and child. Twenty-six children completed all parts of the study that involved two sessions using the Ecolab, a written and verbal pre- and post-system-use-test, and a delayed post-test 10 weeks later. The children's school assessments were used to allocate each child to one of three ability groupings: High, Average and Low. One aspect of the evaluation looked at whether the different variations of the Ecolab had been more or less effective in increasing the child's learning gain in terms of her understanding of the feeding relationships which exist in a food web reflected in the pre- and post-test data. This indicated that ability and the system variant that the child used was relevant to her subsequent learning gain. While the VIS system produced the best overall learning gains, the WIS system produced the highest learning gains for the most able students and the NIS system produced the highest learning gains for the least able group (see Luckin and du Boulay, 1999 for a detailed discussion of these results).

Each time a child used the Ecolab her activity was logged and it is the analysis of these $\log$ s that we concentrate our attention on. And within those logs, it is the character of the interactions between each child and the system that we will focus upon here. For each child an annotated summary record of their interactions was produced from the detailed logs maintained during their two sessions of system use and this was used to build up a picture of the types of interactions each child experienced with the system (for full information see Luckin, 1998). The analysis of these annotated interaction summaries of children's experiences with the Ecolab software enabled us to classify children according to the nature of their experiences with the system. Two aspects of this classification appropriate to the current discussion are Interaction and Collaboration, with the children who took part in this study being categorised into

1. Interaction Profiles according to the character of their interactions with the Ecolab. 
2. Collaboration Profiles according to the nature of the collaborative support provided by the system for the child.

\section{Interaction profiles}

Interaction profiles were organised along three dimensions: business-quietness, exploration-consolidation andhopping-persister. Each child was allocated a position along each of these three dimensions. The terminology for the dimensions was chosen for its evocativeness: the terminology is not intended to be judgmental.

The three dimensions of categorisation: Busy/Quiet, Exploration/Consolidation and Hopper/Persister bear some similarity to features found in other categorisation systems. Pask's differentiation of "top-down" holists from "bottom-up" serialists (Pask, 1976) shares some common ground with the Hopper/Persister characteristic, for example. The differentiation of exploration from continuing activity at a level of consolidation is likewise similar to the challenge/safety division of Groat and Musson (1995). However, the motivation for the analysis reported in this paper was not the presentation of a generally applicable categorisation system. The aim was twofold:

1. To investigate the relationship between interaction style and learning gain.

2. To examine how each of the system variations of the Ecolab supported and encouraged particular learning styles.

Busyness was considered to be a characteristic of interactions in which the child completed an average or above average number of actions of any type, such as adding an organism to their Ecolab world or making one organism eat another. The interaction summaries of these children contained an above average number of events. The opposite of Busyness is referred to as Quietness.

Exploration was considered to be a characteristic of an interaction if the child had been involved in some sort of action which allowed her to experience more than one level of complexity or more than one level of terminology abstraction, beyond her initial starting levels. The opposite of Exploration is referred to as Consolidation.

Some children also switched frequently from one type of interaction to another. For example, they might switch from attempting to make one animal eat another, to looking at their organisms in a different view, to accessing a new activity entirely. Their interactions contained no, or few, series of repeated actions of the same type. They 
were particularly prone to frequent changes of view. These users have been characterised as hoppers. Other learners exhibited a more persistent approach, with sets of actions of a similar type grouped together. These users have been referred to as persisters.

These three binary characteristics allow each child to be categorised into 1 of 8 possible Interaction Profiles. Children fell into 6 of the 8 possible Interaction Profile groups. The distribution within these groups is illustrated in Table 2. The following subsection illustrates the largest of these interaction profile categories, namely that of BusyExploring-Persisters. Details of the other of the members of the other profiles can be found in Luckin (1998).

Table 2. Interaction Profile Membership $(\mathrm{N}=26)$

\begin{tabular}{|l|r|}
\hline Profile Description & \% of children in Profile group \\
\hline Busy - Exploring - Persister (BEP) & $28 \%$ \\
\hline Busy - Exploring - Hopper (BEH) & $12 \%$ \\
\hline Busy - Consolidating - Persister (BCP) & $8 \%$ \\
\hline Busy - Consolidating - Hopper (BCH) & $12 \%$ \\
\hline Quiet - Consolidating - Persister (QCP) & $20 \%$ \\
\hline Quiet - Exploring - Persister (QEP) & $20 \%$ \\
\hline
\end{tabular}

Interaction Profile Example

S10 (Gene) was a typical example of the Busy - Exploring - Persister style of interaction. Her first action was to switch from world view to energy view and then back to world view. She then added 15 organisms to the Ecolab and visited the energy view again. Upon switching back to world view she made one of her organisms eat another, switching to energy view to see the effect. This pattern of making organisms act, either eating or moving and looking at the effect in an increasing number of different views continued. Introductory, investigative and rule-definition activity types were completed for the first two nodes in the curriculum before her first session drew to a close. She chose not to save her current Ecolab world which meant that at the start of her next session her first actions were the addition of organisms. Once again she added all 15 and then moved into the next phase of food web complexity and used more abstract terminology to view her organisms. Whilst the nature of the actions she completed was now more advanced and several instances of help were used, her pattern of activity remained one of initiating an action or actions 
appropriate to the evident goal. Actions were often completed in pairs and were followed by viewing the result from different perspectives (most commonly, energy, web and world). She did not experiment with writing a program or attempt to "escape" from completing the activities offered to her.

This profile group contains only high and average ability children from the VIS and WIS system user groups. In terms of performance at post-test there was a tremendous spread: A Busy - Exploring - Persister style learner attained the lowest learning gain ($4.1 \%)$, another, the second highest learning gain (32.5\%). To put these figures in context, the mean learning gain across all users was $11.8 \%$, though the interaction profile cell sizes were too small to compute significant differences. The high ability children within the group all achieved an above average learning gain $(12.6 \%, 17 \%$ and $32.5 \%$ ), but within the average ability children there was a wider spread of learning gain scores $(24.8 \%, 12.3 \%, 4.2 \%$ and $-4.1 \%)$. Membership of this group was limited to VIS and WIS users, of whom the VIS users both achieved above average post-test learning gains $(24.8 \%$ and $12.6 \%)$, including the highest learning gain within this user group.

\section{Collaboration profiles}

Two characteristics were found to be the most useful for categorising collaborative style within the interactions: Amount of support and Depth of support used. These collaboration characteristics were used to group the children into one of four Collaboration Profile groups.

Amount of support: the average amount of activity differentiation and the average number of help instances for the experimental group was calculated. An above average amount of either activity differentiation or instances of help was the criteria necessary for a child to be considered as using 'Lots' of collaborative support.

Depth of support: this characteristic was based upon the level of help and level of differentiation used. Once again the average levels used within the experimental group were calculated. Help or differentiation above the average level resulted in a child being considered as using 'Deep' or higher level support.

Interactions could be grouped into all four of the possible Collaboration Profiles. The first group was the largest and was further divided in accordance with the type of support which was most prevalent. The distribution of children into these groups is illustrated in Table 3.

Table 3. Distribution of children within Collaboration Profile groups $(\mathrm{N}=26)$ 


\begin{tabular}{|l|l|l|l|}
\hline Profile Description & $\begin{array}{l}\text { \% of children } \\
\text { in Profile }\end{array}$ & $\begin{array}{l}\text { Profile sub- } \\
\text { group } \\
\text { Description }\end{array}$ & $\begin{array}{l}\text { \% of children } \\
\text { in Profile } \\
\text { sub-group }\end{array}$ \\
\hline Lots and Deep (LD) & \multirow{2}{*}{$\begin{array}{l}\text { Differentiation } \\
\text { and Help }\end{array}$} & $19 \%$ \\
\cline { 3 - 5 } & & Differentiation & $19 \%$ \\
\cline { 3 - 5 } & & Help & $15 \%$ \\
\hline Lots and Shallow (LND) & $12 \%$ & & \\
\hline Little and Deep (NLD) & $16 \%$ & & \\
\hline Little and Shallow (NLND) & $19 \%$ & & \\
\hline
\end{tabular}

Collaboration Profile Examples

S1 (Jason's) use of the available support was typical of the Lots and Deep profile group and of a user of above average amounts of both help and activity differentiation. He used level 4 help early in his first session of system use to achieve success in making organisms eat each other. His initial activities were completed with maximum differentiation of level 3. This was gradually reduced and then increased again. During his first session of system use he completed a range of activities for three nodes in the first phase of the curriculum. All instances of successful help were at level 4 or level 5. Fewer activities were completed during his second session. However, these activities were at a lower level of differentiation and there were fewer instances of help.

The Lots and Deep Collaboration Profile group was the largest and was subdivided to account for the type of support used. Only VIS and WIS system users shared the profile. Jason was a member of the subgroup which used above average amounts and levels of both activity differentiation and help. This subgroup again consisted only of high and average ability children whose mean learning gain was above the average for the whole class ( $16 \%$ as compared to the class average of $11.8 \%)$. The subgroup of children who used greater levels of differentiation than help contained children from all ability groups. This second subgroup also produced above average learning gains at post-test (18\% as compared to the class average of $11.8 \%$ ). The last subgroup of children, who used greater amounts of help than differentiation, were all average ability children. Their average learning gain was well below the class average (3.9\% as compared to the class average of $11.8 \%$ ). 
So far little has been said about the NIS user group; they have not belonged to either of the Profiles used in the examples. Recall that NIS was the system variant where the child had the most autonomy about selecting what to do next and about choosing the degree of assistance (see Table 1). In fact, all the NIS users belonged to a Consolidating Interaction profile; there were no explorers in this system user group. In addition, and as has previously been mentioned, no NIS users were in the Lots and Deep Collaboration profile group.

S9's (Tim's) Interaction profile, which was that of a Quiet, Consolidating Persister, was typical of a NIS system user. His initial session consisted of adding a single snail and then making 11 view changes to look at this organism from all perspectives. This initial stage was followed by a series of organism adding (commonly in blocks of four); single actions, such as 'move' or 'eat' commands, in blocks of one to five; and view changes which were almost always in pairs. In session 2 he adopted the commonly seen approach of adding a considerable number of organisms to start (in this case 12) and then, once again, completing single actions and view changes.

Likewise S26 (Karlie's) Collaboration profile reflecting low use of all types of help (Little and Shallow: NLND) was typical. She placed herself at the far extreme of food web complexity and started dealing with populations of organisms straight away. She only completed one type of action during both sessions of computer use: she built food webs using the build web command. Initially she made errors and used only occasional low level feedback, persisting until successful. The children in this profile group were all of high or average ability, but their average learning gains were well below average (5.2\% as compared to the class average of $11.8 \%$ )

A further difference found within the NIS user group relates to the relationship between ability and learning gain. In the VIS and WIS user groups it was the higher ability children who achieved the greatest learning gains. By contrast, amongst the NIS users none of the high ability children made an above average learning gain; in fact, the only learners who made above average learning gains were the low ability children. Whilst the numbers are small and the study exploratory this result is interesting and is certainly informing our current research. We had expected that of all three systems, the one which left most control within the hands of the learner would be most effective with the more able learners. Our results indicate that the opposite was in fact the case in our study.

What does this case study tell us about modelling and communication? 
The children in this study were not always effective at selecting activities that were appropriately challenging or at seeking the appropriate amount of assistance from the system. It was possible to influence the nature of their modelling activities: the complexity of the models they ran, for example, and the nature of the collaboration that occurred between system and child through manipulating the role played by the computer. Indeed, A Pearson Chi-squared statistical test revealed that the system variation a learner used had a greater impact upon their membership of an Interaction or a Collaboration profile than their ability. There was a significant association between System variant membership and Collaboration Profile membership (Chi-square $=$ 28.52, $\mathrm{df}=6, \mathrm{p}<.0001$ ), and between System variant membership and Interaction Profile membership $($ Chi-square $=25.79, \mathrm{df}=10, \mathrm{p}<.01)$. Table 4 sets out the number of children in each of the Interaction and Collaboration profiles by System variant.

Table 4. Membership of profile categories $(n=26)$

\begin{tabular}{|l|l|l|l|}
\hline Profile & VIS & WIS & NIS \\
\hline Busy exploring persister & 2 & 5 & 0 \\
\hline Busy exploring hopper & 1 & 3 & 0 \\
\hline Busy consolidating persister & 0 & 0 & 2 \\
\hline Busy consolidating hopper & 1 & 0 & 2 \\
\hline Quiet consolidating persister & 0 & 1 & 4 \\
\hline Quiet exploring persister & 4 & 1 & 0 \\
\hline
\end{tabular}

\begin{tabular}{|l|l|l|l|}
\hline Lots and Deep & 9 & 5 & 0 \\
\hline Lots and Shallow & 0 & 0 & 2 \\
\hline Little and Deep & 0 & 4 & 1 \\
\hline Little and Shallow & 0 & 0 & 5 \\
\hline
\end{tabular}

The results above suggest that the nature of the modelling was very sensitive to the variant of the system and to the ability of the particular child. VIS and WIS were able to adjust the degree of abstractness of the terminology used, but none of the systems were in a position to react meaningfully to children's explanations in their own words about what they were modelling. In fact, the children were asked to explain various concepts as part of the post-test and a delayed post-test, and in general they were able to make better explanations after their experience with the system (of whichever variant). So while some features of the communication between child and computer were under the control of either the child or the system, there were, in the end, strong limitations in 
the extent to which the children could explicitly contextualise with and through the system what they were learning against the background of what they already knew about ecology.

Our second case study begins to address this issue. Here the students worked in groups, discussing with each other, and writing a freeform textual answer to a given question. These students could engage in unrestricted communication with each other, and an aspect of interest in the second case study is how system features affect that communication. Of course, the second system has its weak points too: notably that students cannot test their understanding by running and debugging a simulation.

\section{Case Study 2: Galapagos: discussing modelling}

\section{The Galapagos CD-ROM}

The second case study we discuss involves a CD-ROM called Galapagos. This was developed as a research tool to aid our investigations into the impact of narrative on children's learning with Multimedia Interactive Learning Environments (MILEs). It provides learners with a multimedia account of Darwin's visit to the Galapagos Islands and the theory of evolution he developed as a result. Learners are set the task of using the resources provided on the CD-ROM to construct an explanation of the variations in the wildlife on the islands in an on-line notepad. The notepad is the location of the modelling activity in this case study and the form of the model is a textual narrative rather than a runnable simulation as in Ecolab. The elements which learners can use to construct this text are the resources on the CD-ROM and the resources each of them brings to the situation and shares. In this example, as in Case Study 1, learning is collaboration, but the parties involved are different. They are the learners working as a group around the computer with the CD-ROM. The system does still provide some scaffolding to assist the learner's progress, but in this instance the support is adaptable by the learners rather than adaptive to the learners.

The resources on the CD-ROM are also of a different nature to the action commands and runnable model elements of the Ecolab. There are 8 sections of content material on the CD-ROM, each of which deals with a particular aspect of Darwin's visit. For example, there is a section which describes his arrival and first impressions of the Galapagos islands, and sections about the identity of the different islands and the different varieties of finch which lived in these different locations. The full set of 
sections is as follows; the section numbers are used to refer to sections throughout this paper, but were not part of the structure presented to our users:

Introduction

Section 1: About Darwin's visit

Section 2: About Islands

Section 3: Island Formation

Section 4: Island Location

Section 5: Trade Winds

Section 6: Currents

Section 7: About the Birds

Section 8: Explore the Islands

As well as having a role within the overall story about Darwin's work on evolution, each of these sections also offers its own possibilities for interaction, in the form of movies to play or images to click on for feedback. In addition to these sections of content material users can access the following five features to assist them via a tool bar at the bottom of the screen as illustrated in Figure 2. (For more detail about all the Galapagos features see Plowman, Laurillard, Stratfold, \& Taylor, 1998):

1. A reminder about the task they have been asked to complete at the outset of their interactions with Galapagos.

2. An editable Notepad in which they can take notes and write their answer: the focus of their modelling activity in this case study.

3. A Model Answer which is a sample of an acceptable answer to the task they have been set and which can only be accessed when they have written 50 words in the notepad.

4. A script window which contains the transcript for all audio material in the CD-ROM.

5. Some navigation options that allow navigation to be varied in accordance with the actions selected by the learners as appropriate to the sub-goal with which the group is currently operating.

We used Galapagos with groups of students, aged between 15 and 21 years, all of whom were studying for a national examination in Biology. A session using Galapagos and completing the task (to explain the variation in the wildlife on the Galapagos Islands and write the answer in the notepad) to their own satisfaction typically took about 45 minutes. The following scenario describes the sort of experiences learners had with Galapagos: 
The first thing that Mark, Claire and Louise do after the initial introduction (which includes the specification of the task) is to access the task again and discuss what it is they have got to do. They then return to the introduction which involves hearing the task again. Between 2.19 minutes and 14.37 minutes (34\% of the total session time) the group starts to construct a notepad answer. They access the guide and through this facility they move on to content section 8 of the CD-ROM, they open the notepad and then section 2 of the CD. Initially (2.19 - 5.29 minutes $)$ talk is about what completing the task involves. This is followed by a move back to the introduction and therefore another experience of the task. At 4 minutes the search engine is used and section 2 of the CD-ROM is accessed. Activity between 4.09 and 14.37 minutes (29\% of total session time) consists of alternating between section 1 of the CD-ROM and the notepad, with one look at the task as well. As they watch section 1 of the CD-ROM, they start to type into the notepad and the discussion is about what they should write, picking up points from the audio track. At 14.54 minutes they go back to the introduction again and then to the task and in this way they hear the task twice. At 14.54 minutes the search engine is used to reach section 7 of the CD-ROM. Discussion is about how the section on the different birds relates to the task. The notepad is not used after this, but is opened again at 19.09 minutes after the guide has been used and section 2 of the CD viewed. They talk about the importance of the Galapagos being an island and how this relates to the task. Until the model answer is opened at 28.04 minutes activity consists of using the guide to access sections 3,5 and 6 of the CD-ROM, and further completion of an answer in the notepad. About 50\% of the talk is about the completion of the task. The features of the CD-ROM section and their relationship to the model answer are discussed. Once the model answer is accessed section 2 of the CD-ROM is opened and some revisions made to the notepad.

As in the Ecolab system in Case Study 1, Galapagos was implemented as three different system versions. However, in this case the manipulation is with respect to the presentation of the same content material. Specifically, it relates to number 5 in the list above, navigation options: the amount of guidance the system provides to users to help 
them navigate through the available material is varied. The three versions Galapagos versions are called: Linear, Resource Based Leaning and Guided Discovery Learning.

1. Linear: When the material on this version is first viewed the system moves automatically between the content sections. After this, learners can elect to go back to certain selected points within this presentation and from there, they can move either backwards or forwards between the different sections of content. It provides no full menu or search facility and no overview of the structure of the CD-ROM. The navigation options available on the tool bar of this system variation are: back and forward.

2. Resource-Based Learning (RBL): Learners have free access to all sections of the CD-ROM through a menu and free text search facility. The navigation options available on the tool bar of this system variation are: menu and search.

3. Guided Discovery Learning (GDL): The menu is expanded into a textual guide which breaks the initial task down into sub-tasks and suggests the relevant sections of the CD-ROM to access for information about these sub-tasks. The navigation options available on the tool bar of this system variation are: guide and search. 


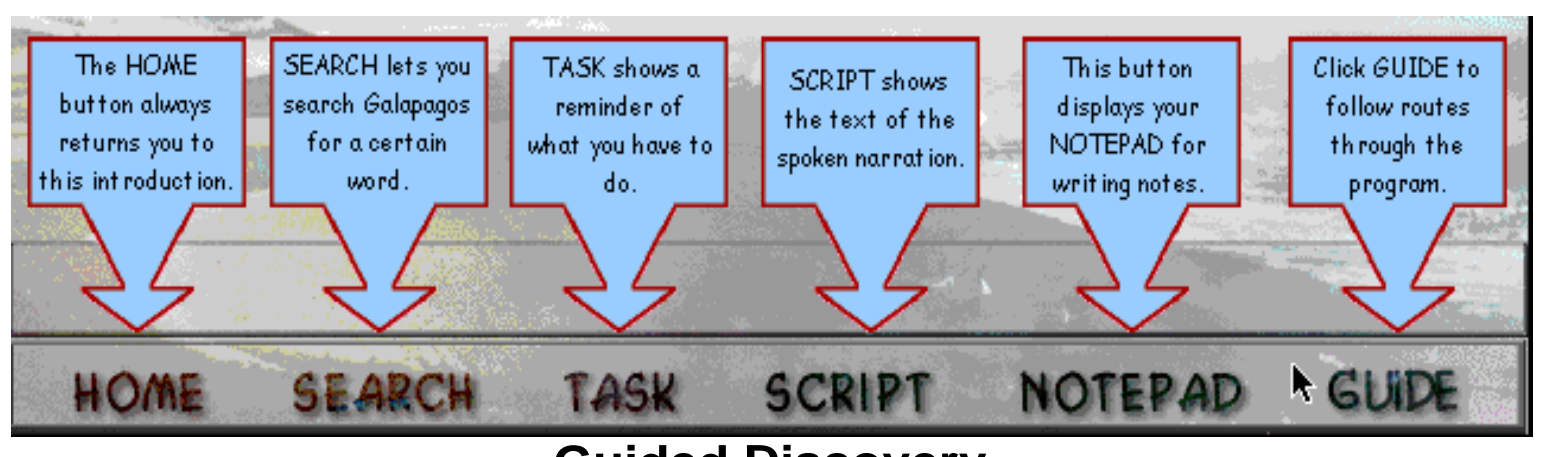

\section{Guided Discovery}

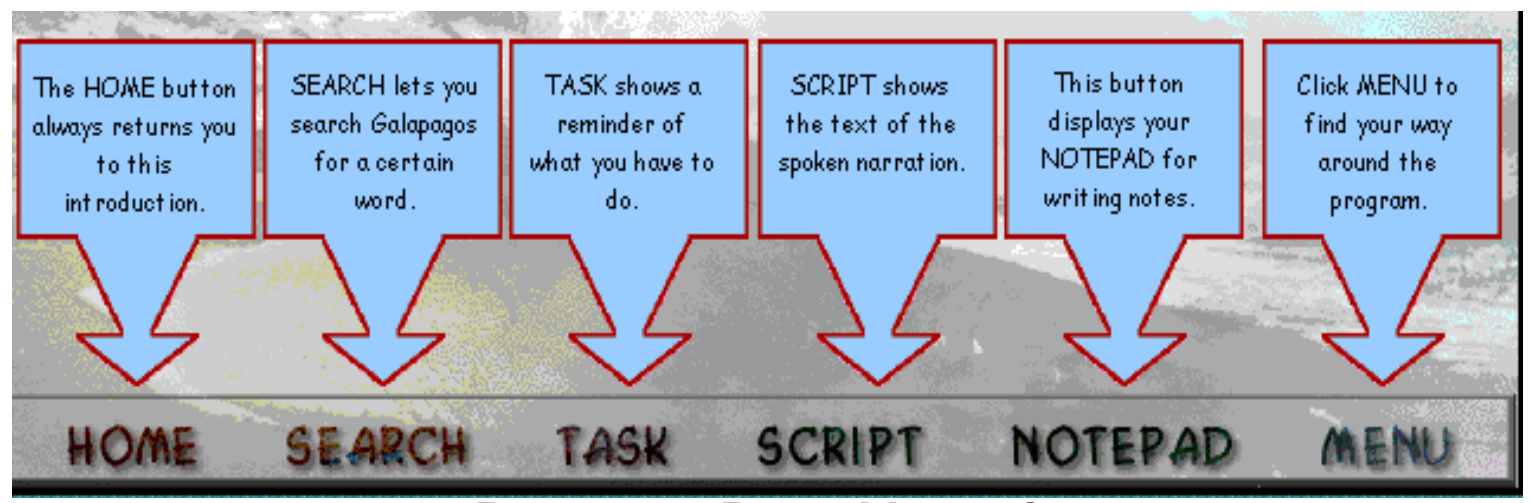

\section{Resource Based Learning}

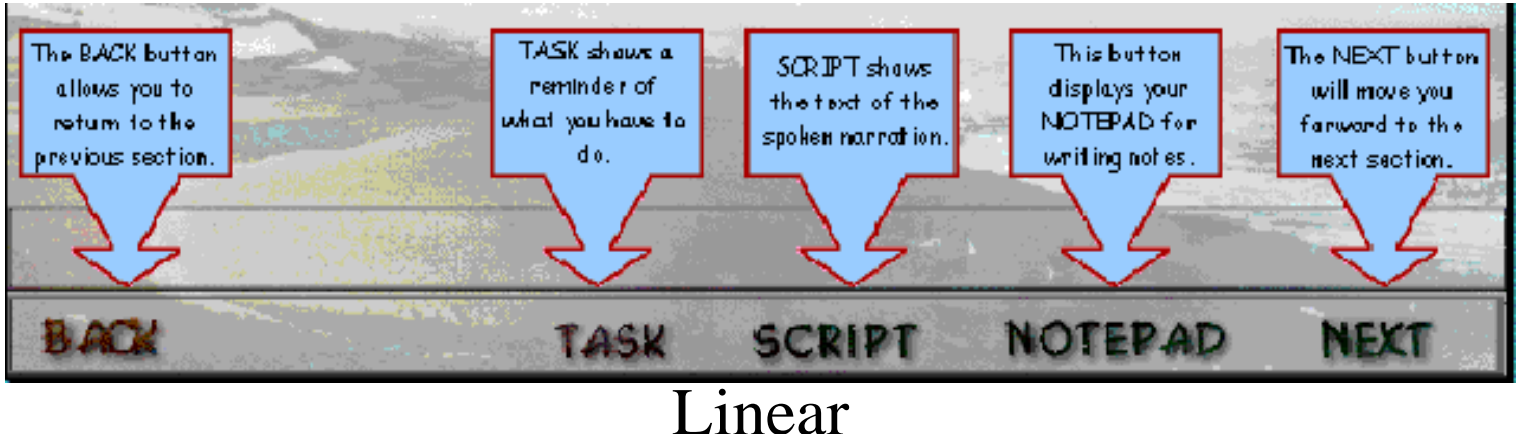

3 versions of the Galapagos Introductory Screen

Figure 2. Galapagos Tool Bars

These three versions were developed in order to enable us to observe the impact of presentational variation upon learner interaction. For the purposes of our discussion in this chapter, they allow us to explore the nature of the system features that supported communication between learners and assisted their construction of an answer: a model of their understanding.

\section{Empirical Evaluation: Interactions around Galapagos}

The groups of learners using Galapagos each used only one of the three system versions. Each group consisted of three learners of differing abilities, selected by the 
class teacher. The number of students in our study was small and it was not our aim to adhere to a pre- test/post-test experimental methodology but rather to concentrate on process issues. Thirty-six learners used Galapagos as part of their course of study at a time when it was pertinent to their curriculum objectives. The interactions around the computer were complex and we wanted to increase our understanding of the process learners went through when they used the CD-ROM. It was therefore our goal to study each of our groups in detail and we used video as one of our sources of data. We recorded every group session from two video-sources: one recorded the group of learners at the computer to capture talk, movement, gesture and machine interaction; the other was the screen image, taken from the computer via a scan converter.

Video provides a flexible source of data for analysis. However, the richness of the data, whilst enormously valuable, can be overwhelming. In order to cope with the overwhelming density of information and to try and ensure that a) particularly interesting moments in the interactions can be located quickly at a later date, and b) sufficient contextual information about these moments can be found quickly, we developed a number of charts and graphs as tools for representing different aspects of the interactions (see Luckin et al., 1998, for more detail about the methodology and analytical tools used). In this chapter, we concentrate our discussion upon dialogue analysis in combination with one of these representations: Answer Construction Records (ACR). ACRs record the time and content of each text entry made by the group into the notepad and the system features used around this text entry.

\section{The dialogue between learners as they use Galapagos}

The dialogue was transcribed and categorised. The categories used were informed by our early observations of commercial CD-ROMs and the questions we wanted to explore. With respect to educational focus, these categories enabled us to:

- differentiate the times when learners are focusing on the medium of communication: on procedural or operational issues, from the times when they are involved in the pragmatics of answer construction, and

- to determine the times when they are trying to construct an understanding of the underlying concepts about evolution.

There is a wide variety of work which considers the structure of the exchanges within dialogue, the nature and quality of the argumentation, or the negotiation which occurs between participants (Quignard, 1999; Ravenscroft, 1999; Chi, 1997; Pilkington, 1999, for example). It would certainly be interesting to explore the structure of the 
dialogues surrounding the use of Galapagos, but such work has been beyond the scope of our analysis to date.

Two researchers acting independently but using the same system of categorisation completed all coding of dialogue. Discrepancies were few and were discussed in order to reach a consensus about the final coding category to be used. The dialogue was categorised initially into Non-Task, Task and Content.

1. The Non-Task category encompasses navigational and operational talk other than that which relates specifically to using the notepad or model answer e.g. "click on one" "play" for video or audio clips. This category focuses on the use of system features and learners' interactions with the operational aspects of the system rather than the content.

2. The Task category includes dialogue about the pragmatics of answer construction, about getting the task done rather than what to put in the answer. For example, discussions about how and when to use the notepad e.g. "shall I type?". The focus here is on specific software features such as the notepad and model answer. Here learners are negotiating the use of tools, which should enable them to interact with the content and construct an understanding of these concepts.

3. The Content category of talk includes all discussions about Darwin, the Galapagos islands and evolution, both specifically related to constructing a group's answer and in general.

There were very few examples of instances where dialogue fell into more than one category. These were entirely restricted to humorous comments that might for example be flippant and yet relate to content. Each of these categories was then sub-divided for a more detailed analysis. Discussion of this is beyond the scope of this paper, but can be found in (Plowman, Luckin, Laurillard, Stratfold, \& Taylor, 1999).

\section{What support did Galapagos provide for modelling and communication?}

The goal of our analysis was to construct an understanding of what was happening at the system interface; what was happening between individual learners in the group; and what sort of an understanding individual learners were constructing as a result of these collaborative interactions. Here we concentrate on how the system supported communication and model building in the notepad.

\section{Did learners focus on domain concepts or interface operation?}


In order for learners to construct a model of their understanding, they need to interact with the concepts of the domain rather than the operations of the medium. The discussions conducted by all groups of learners contained twice as much Content type talk as talk categorised as Non-Task or Task. Likewise, with respect to notepad use, over $25 \%$ of the total discussions between learners took place when the notepad editor was open on the screen and more than $10 \%$ when the model answer had been accessed and was open on the screen. Talk about navigational and operational issues (i.e. categorised as Non-Task dialogue) for all groups occurred throughout all but one content section of the CD-ROM as learners discussed when and how to play a particular video clip for example. Discussion about how to complete the task (i.e. categorised as Task dialogue) was however less evenly distributed amongst these same content sections.

The following transcript excerpt is taken from a group of learners using Galapagos and illustrates conversation clearly focused upon the current task.

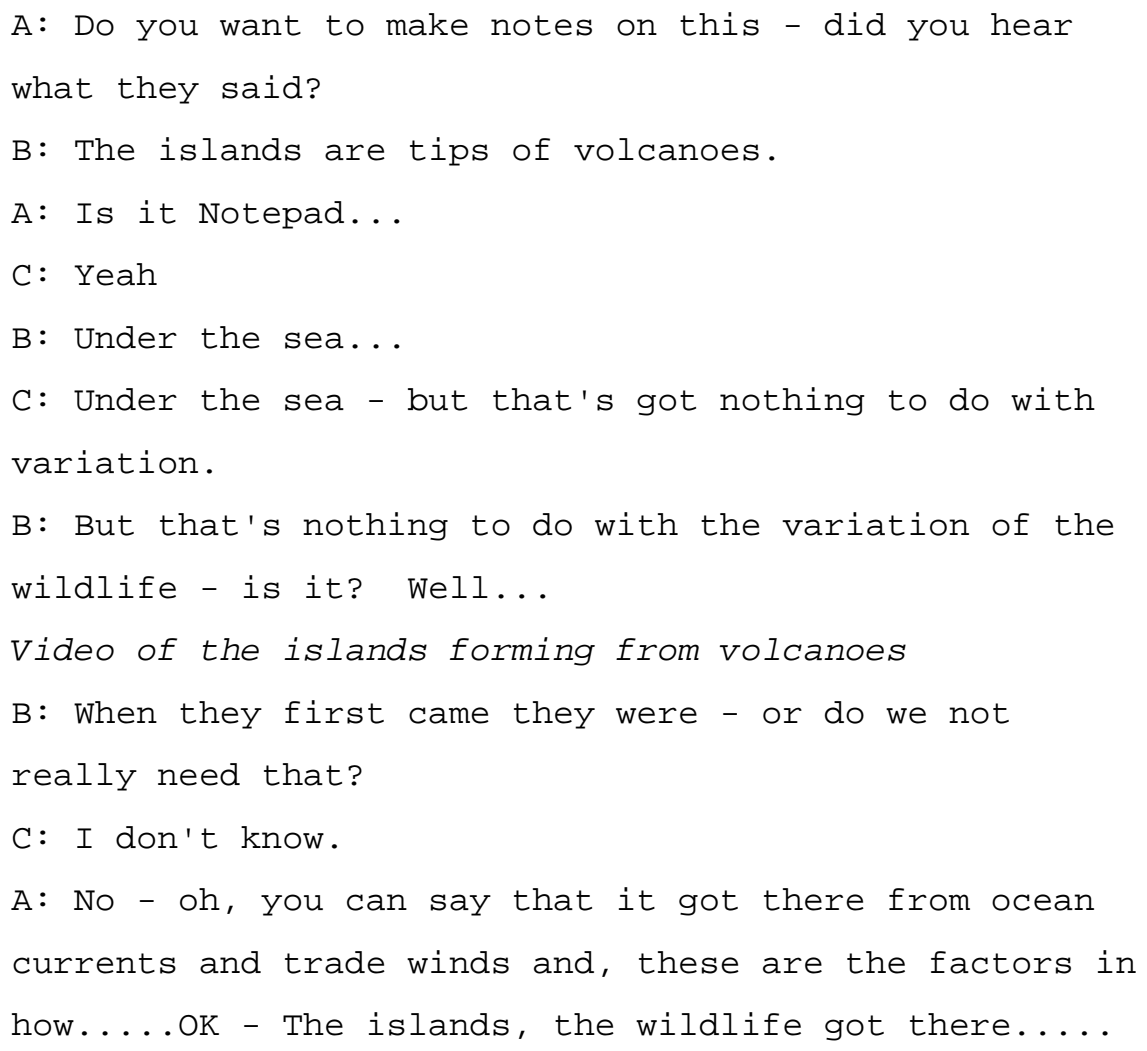

The learners had been asked to explain the variation in the finches on the Galapagos Islands. The group searched for information relevant to their task and when they found it they recognised its relevance and continued to construct a narrative of their understanding of how the variations in the Galapagos wildlife occurred. 


\section{How did learners use their own articulations to co-construct their descriptive model?}

All the groups of learners using Galapagos were required to construct their answers as a collaborative effort. There were many clear instances of productive collaborations. The transcript below is taken from a group who had just viewed a video clip about ocean currents and are starting to construct their text in the notepad. During the latter part of this conversation the following text was entered: "the wildlife's population increased because of ocean currents, trade winds. the islands were formed from volcanic action underneath the sea so they were just rocks."

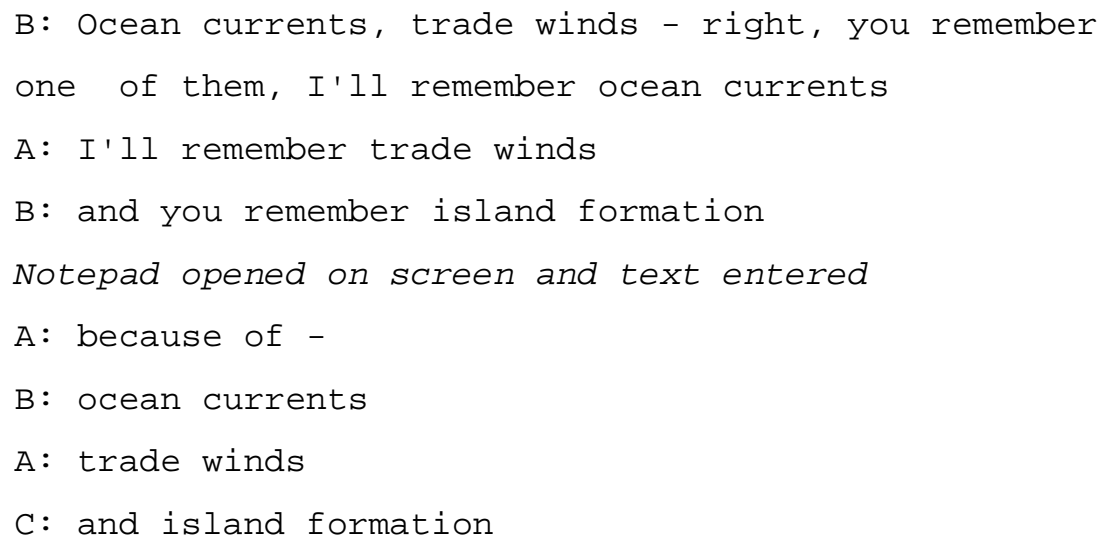

The teacher later assessed the unattributed written response and commented of this group: "I like this answer a lot. This is obviously written in their own way, rather than taking chunks from the video, and they go through it in a very ordered manner." The clear statement of the goal allowed the learners to keep it in mind whilst constructing their response helping them to avoid getting side-tracked. The notepad allowed them to record each of their contributions within the answer and the constant availability of the task provided a reminder.

\section{How did learners use the system's model of an answer to revise their own articulation?}

The model answer was designed to offer feedback on learners' conceptions, motivate reflections on their response, encourage collaboration, and allow revisions to the learners' own answer. Attempting to open the model answer before sufficient text was entered into the notepad resulted in learners being advised that they could only access 
the model answer when they had typed 50 words into the notepad editor. Only one of the groups who accessed the refusal message started to enter text prior to this point, and in all cases the notepad was opened and text entered within a very short period of time (under 3 minutes). The following extract (see Table 5) is an $A C R$ extended to include dialogue. It illustrates the activity of one group of users following the model answer refusal message that was seen after 9 minutes of CD-ROM use. The students open the task window, read the task aloud, then open the notepad and start to enter their answer. 
Table 5. Learner's activity after accessing model answer refusal

\begin{tabular}{|c|c|c|c|}
\hline Time & Notepad text entered & Dialogue & Screen \\
\hline \multirow[t]{2}{*}{ (mins) } & The animals on the & A: The animals on the islands all vary, & Note - \\
\hline & island varie & $\mathrm{C}$ : the animals on the islands vary, um & pad \\
\hline \multirow[t]{3}{*}{11.29} & & -- (B types and is told to use two hands by C)-- & open \\
\hline & & A: The animals on the island all vary. & \\
\hline & & C: Yeah that will do (laughter). ….... What did you do that & \\
\hline \multirow[t]{3}{*}{11.56} & & for $\mathrm{B}$ ? & \\
\hline & & B: Where did it go? & \\
\hline & & A: what are you trying to do, delete something? & \\
\hline \multirow[t]{6}{*}{12.15} & due to & B: There you are ........ - due to? & \\
\hline & & A: I dunno, something like evolution or something to sound & \\
\hline & & good & \\
\hline & & B: Due to the change in habitat & \\
\hline & change in habitat & B: - due to habitat - & \\
\hline & & A: Oh brits is getting along there & \\
\hline \multirow[t]{4}{*}{12.32} & & A: Due to the habitat and, and what I don't know & \\
\hline & climate & C: Habitat, weather & \\
\hline & & A: Climate, climate and & \\
\hline & & C: Habitat climate and what's the other one - ? & \\
\hline \multirow[t]{2}{*}{12.49} & and prediters & A: Predators & \\
\hline & & C: Yeah predators & \\
\hline
\end{tabular}

The existence of a model answer motivated learners to start constructing an answer of their own but, once opened, it also prompted revisions. The dialogue extract below illustrates how one group discussed these revisions. The model answer is accessed after 33 minutes of system use. The notepad and the model answer are open on the screen and this dialogue occurs in the next couple of minutes. The group adds the following sentences to the start of their own answer: "The island was created by Volcanic activity. This means no wildlife was there to start off with. The islands are on the Equator so there are strong winds and water systems. The wildlife now found on the islands probably drifted over on rafts from America." 


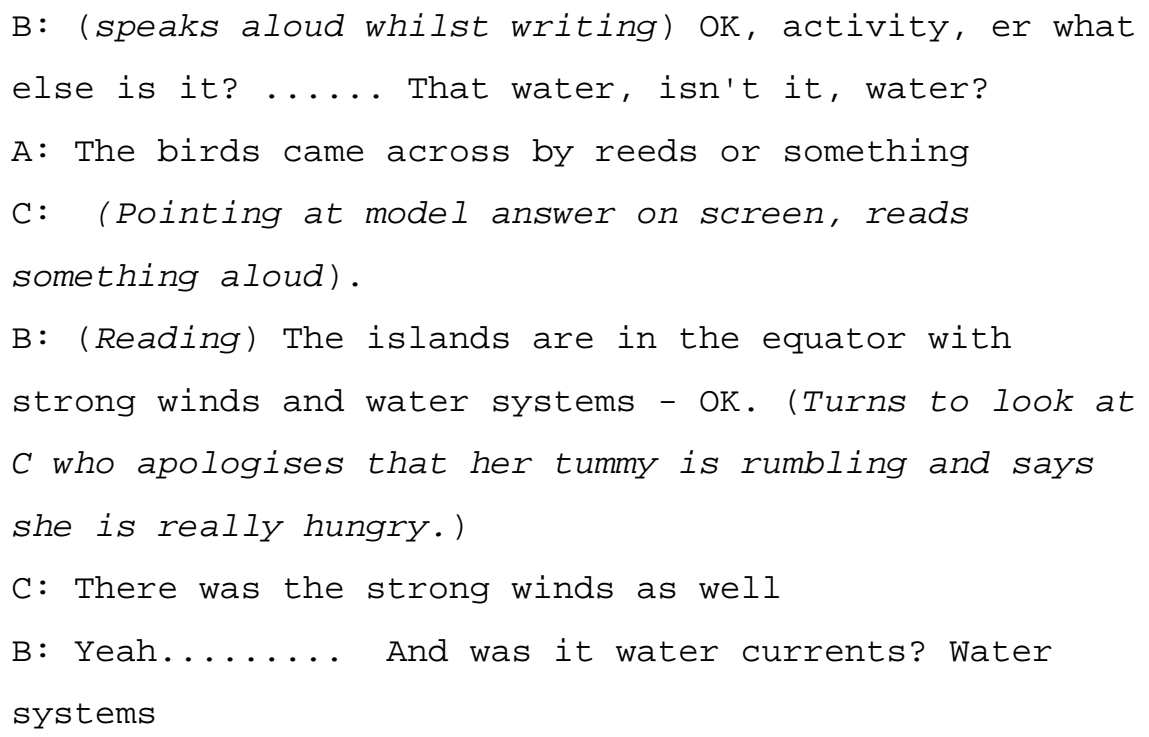

In these brief examples we have paid attention to the communicative processes revealed within the dialogue amongst the groups of students as they collaborate to produce a coconstructed textual narrative. Different groups of learners adopted different approaches and varied in the way they used the available resources both those provided by the CDROM and those provided by each other.

\section{What differences did the three versions of Galapagos have on learner interaction?}

So far we have considered learners' interactions with Galapagos without taking into account the existence of the three different versions. Here we consider the impact of these variations and summarise their effects on learner interaction and communication:

- The Menu in the resource-based version provided free access to all sections of the material, but, unlike the Guide (in the guided discovery version), it gave no guidance on how sections related to each other. This left less confident learners without support for linking the parts together to construct their own textual representation and did not motivate sufficient discussion of these relationships between learners to compensate. These Resource-based learners were further disadvantaged as they were more likely to miss key sections of the material, being entirely self-directed via the Menu. This meant that the groups of learners neither interacted with the information in these sections, nor discussed the concepts presented. In contrast, both linear and guided discovery learners were exposed to all of the material. The resource-based version was highly interactive, requiring students to be very pro-active in what they spent time on. 
They felt they had learned a lot, though in fact learners with low prior knowledge could not complete the full analysis required for construction of the answer. This was further compounded by the fact that in several cases they had not covered all the material. The tools provided in this version were insufficient to support these learners in their model building activity and left them vulnerable to misconception.

- The pre-defined Guide in the guided discovery version tended to focus learners' notes on the essential activities and thus aided abstraction. The more open-ended choices of the resource-based version elicited notes on incidental facts which were more difficult for less able learners to integrate into their own understanding. As with the resource-based version we found that not all the students who had little prior knowledge were able to build the top-level answer with the guided discovery version. They were however able to use the Guide to construct the building blocks beyond the simple facts, namely, to the level of the component relations identified in the sub-goals offered (such as the differences observed between birds on the islands and those on the mainland, and the different weather conditions on the islands relating to variations in species).

- The continual requirement to decide on the next action, in both resource-based and guided discovery versions, encouraged learners to open the Notepad early and take notes as they progressed, and begin to build their own articulated account. This was totally absent for the linear groups. Learners were much more likely to refer back to other sections as they constructed their answers within the learnercontrolled resource-based and guided discovery versions, and therefore tended to use quotes from the material in their notes, which linear users did not do.

- The linear version certainly did engage learners in the pre-constructed narrative. In fact, they never disturbed the sequence, and did not use the Notepad until they had seen all sections. This did however, leave some learners unable to articulate their own understanding except as recall. There was very little communication between learners about either operations or concepts until the sections had been viewed once and the answer construction process began. In the individual audio recorded follow-up sessions we found that only those students with good prior knowledge of evolution were able to maintain the link between this high-level narrative line and the specific information provided in the multimedia material. For the others, the full control by the program for the sequence, and hence the lack of requirement for them to plan their own investigation, or articulate their understanding, reduced their clarity about the relationship between the immediate information and their overall goal. 
Clearly the nature of the direction provided by the system has an impact upon the usefulness of particular system features as tools in the answer construction process. Variations in this direction can also motivate different quantities and qualities of communication between learners about the concepts at the root of that answer.

\section{Discussion}

At the start of this chapter we defined Interactivity as the cycle of operational or conceptual exchange between two or more parties, one of which may be a digital system. We stressed the importance of Interactivity through the interface between users and the subject matter concepts that make up the discipline of study. We have used case studies of both systems to tease out some of the factors that have proved successful in linking support for learning, as communicative competence, and the process of modelling. Both systems have been evaluated using methodologies that yield a rich source of data about the way in which students used the systems as well as the models they constructed. This allows us to explore similarities and differences, and to focus in particular upon the nature and role of the communicative interactions engendered by these systems. In the first, communication is between learner and system, in the second the system's role is different and is to motivate communication between users around the system. In both cases there is an explicit attempt to engender conceptual interactivity with the scientific concepts of the domain through the features of the system. A striking factor of both case studies is that the majority of the learners were both engaged and hard working. Another striking factor was that differences between system variants produced differences in the manner of working. In Ecolab, NIS users were consolidators rather than explorers, and a similar phenomenon was found with Galapagos where the Linear version produced the most constrained traverse of the material.

Neither system was designed to support fully all aspects of modelling in science. Ecolab provided the tools for pupils to manipulate a simplified world. It acted as the more able partner in an interactive interchange where it could make adjustments of various kinds so as to maintain the learners in "vigorous mental activity". It is not unreasonable to regard the interchange between pupil and the system as communication, where each partner in this communication was responding to and adjusting to their perceptions of the other partner. The nature of these adjustments on the system side had strong effects both on the collaborative element of that communication as well as indirect effects on the kind of interaction that ensued. 
In the case of Galapagos the communication between system and student was not subject to dynamic changes on the system side. None of the three variants maintained any kind of internal model that would have allowed adjustments in the Ecolab sense. The variants offered differences in interactivity that were essentially fixed for the duration of the session. Nevertheless different variants produced different kinds of interactive behaviour. In any case the primary focus in this study was not on the communication between the students and the system but on how that communication interacted with the communication between the students, a factor missing in the Ecolab study.

The differences in interactivity between the Ecolab variants was largely conceptual and occurred through the interface. Thus some variants of the system varied the level of specificity of the help that they offered, adjusted the level of complexity of the tasks they set, chose what task to do next and adjusted the degree of abstractness of the terminology used by the system. By contrast, the designed-in differences between the variants of Galapagos were largely operational, at the interface. These consisted of differences in the way that the material on the CD-ROM could be accessed. There is some overlap between conceptual and operational interactivity, but these two case studies indicate that both types of interactivity can have effects on the nature of the communication through the interface and as provoked between participants around the interface.

We return to a point we made earlier. Learning science effectively is a complex process and system design to support this is tricky. Small changes in the interactivity implicit in the design can have large changes on the kind of modelling that takes place. By offering case studies that describe both an adaptive and an adaptable system, we indicate that both kinds of system have a useful role to play and that in both cases attention to the interactivity made possible through the design can crucially affect outcomes.

\section{Acknowledgements}

The Ecolab system was developed with the aid of a grant from the Economic and Social research Council. The research described in the second case study was conducted as part of MENO (Multimedia, Education and Narrative Organisation), funded by the Economic and Social Research Council's Cognitive Engineering Programme, grant no. L127251018. The project was conducted in collaboration with Diana Laurillard, Lydia Plowman, Josie Taylor and Matthew Stratfold. The Galapagos CD-ROM was developed by Matthew Stratfold. We are indebted to the schools, teachers and students 
who made this research possible and to the reviewers, for detailed and valuable comments.

\section{References}

Groat, A. \& Musson, T. (1995). Learning styles: individualizing computer-based learning environments. Association for Learning Technology, 3(2), 53-62.

Guzdial, M., Colander, J., Homely, C., Narayanan, H., Carlson, D., Rapine, N., Hubscher, R., Turns, J., \& Newstetter, W. (1996). Computer support for learning through complex problem solving. Communications of the ACM, 39(4), 43-45.

Jackson, S. L., Stratford, S. J., Krajcik, J., \& Soloway, E. (1996). A learner-centred tool for students building models. Communications of the ACM, 39(4), 48-50.

Laurillard, D. (1993). Rethinking university teaching: A framework for the use of educational technology. London: Routledge.

Luckin, R. (1998). 'ECOLAB': Explorations in the Zone of Proximal Development (Thesis: CSRP Technical Report 486): School of Cognitive and Computing Sciences, University of Sussex.

Luckin, R., \& du Boulay, B. (1999). Designing a Zone of Proximal Adjustment. International Journal of Artificial Intelligence and Education, 10(2), 198-220.

Luckin, R., Plowman, L., Gjedde, L., Laurillard, D., Stratfold, M., \& Taylor, J. (1998). An Evaluator's Toolkit for Tracking Interactivity and Learning. In M. Oliver (Ed.), Innovation in the Evaluation of Learning technology (pp. 42 - 64). London: University of North London.

Pask, G. (1976). Styles and strategies of learning. British Journal of Educational Psychology, 46, 128-148.

Plowman, L., Luckin, R., Laurillard, D., Stratfold, M., \& Taylor, J. (1999).

Designing Multimedia for Learning: Narrative Guidance and Narrative Construction. In the proceedings of CHI 99, 310-317.

Rosson, M. B., \& Carroll, J. M. (1996). Scaffolded examples for learning objectoriented design. Communications of the ACM, 39(4), 46-47. 
Vygotsky, L. S. (1978). Mind in society: the development of higher psychological processes. Cambridge, MA: Harvard University press.

Vygotsky, L. S. (1986). Thought and Language. Cambridge, Mass: The MIT Press.

Wood, D., \& Wood, H. (1996). Vygotsky, tutoring and learning. Oxford review of Education, 22(1), 5-16. 